\title{
Relationship Between Screen Time and Mother-Child Reciprocal Interaction in Typically Developing Children and Children with Autism Spectrum Disorders
}

\author{
Murugesan Krupa ${ }^{1} \cdot$ Prakash Boominathan $^{1} \cdot$ Padmasani Venkat Ramanan $^{2} \cdot$ Swapna Sebastian $^{3}$
}

Received: 19 June 2018 / Accepted: 13 December 2018 / Published online: 9 January 2019

(C) Dr. K C Chaudhuri Foundation 2018

To the Editor: Resources available in television and smart phones may be useful in learning context. However, excessive exposure to screens may have adverse effects on young children. Direct exposure to screen influences development of behavior [1], language [2], cognition [3] and attention [4] in other-wise typically developing children (TD). The impacts could be profound in children with autism spectrum disorder(ASD) who already have communication and socialization difficulties [5]. In addition, distracted communication partners (providing divided attention or inattention to the child) disrupt reciprocal interaction between the child and the partner. Thus, apart from children's screen time, the impact of family's screen time in TD children and children with ASD is important. This study explored the correlation between reciprocal interaction and family screen time using a cross-sectional study design.

Children with ASD $(n=46)$ and TD children $(n=46)$ between 2 and 4 y of chronological age participated in the study along with their mothers who were the primary caregivers. Duration of child's direct screen time and family's total screen time was calculated based on parental report, following which a $40 \mathrm{~min}$ free play between each child and their mother was video recorded at home. Pearson's co-efficient of correlation was used to compare duration of reciprocal interaction with that of child's direct screen time and family's screen time.

Results indicated a overall negative correlation between family screen time and duration of caregiver-child reciprocal interaction

Padmasani Venkat Ramanan

padmasani@sriramachandra.edu.in

1 Department of Speech Language and Hearing Sciences, Sri Ramachandra Institute of Higher Education \& Research (Deemed to be University), Porur, Chennai, Tamil Nadu, India

2 Department of Pediatric Medicine, Sri Ramachandra Institute of Higher Education \& Research (Deemed to be University), Porur, Chennai, Tamil Nadu, India

3 Department of ENT, Christian Medical College, Vellore, Tamil Nadu, India $(r<0.0)$. Families of children with ASD had significantly $(p<0.05)$ longer family screen time $(\mathrm{M}=8.42 ; \mathrm{SD}=2.658)$ than families of TD children ( $M=4.4 ; \mathrm{SD}=1.444)$. Direct screen time of children with ASD $(\mathrm{M}=6.92 ; \mathrm{SD}=2.011)$ was also significantly greater than $\mathrm{TD}$ children $(\mathrm{M}=3.63 ; \mathrm{SD}=1.360)$.

This study implies that in addition to child's direct screen time, family's screen time has a negative impact on motherchild reciprocal interaction. Thus, anticipatory guidance and counseling on the need to restrict family screen time should be provided to families of all children in well-baby clinics and to those with ASD/other developmental delays.

\section{Compliance with Ethical Standards}

Conflict of Interest None.

Source of Funding None.

Publisher's Note Springer Nature remains neutral with regard to jurisdictional claims in published maps and institutional affiliations.

\section{References}

1. Özmert E, Toyran M, Yurdakök K. Behavioral correlates of television viewing in primary school children evaluated by child behavior checklist. Arch Pediatr Adolesc Med. 2002;156:910-4.

2. Chonchaiya W, Pruksananonda C. Television viewing associates with delayed language development. Acta Paediatr. 2008;97:977-82.

3. Zimmerman FJ, Christakis DA. Children's television viewing and cognitive outcomes: a longitudinal analysis of national data. Arch Pediatr Adolesc Med. 2005;159:619-25.

4. Christakis DA, Zimmerman FJ, DiGiuseppe DL, McCarty CA. Early television exposure and subsequent attentional problems in children. Pediatrics. 2004;113:708-13.

5. American Psychiatric Association. Diagnostic and Statistical Manual of Mental Disorders (DSM 5), 5th ed. Autism Spectrum Disorders, 2013; Available at: https://images.pearsonclinical.com/images/ assets/basc-3/basc3resources/DSM5_DiagnosticCriteria_ AutismSpectrumDisorder.pdf. Accessed 10th September 2014. 